\title{
ANÁLISE DO COMPORTAMENTO DE CRIANÇAS VÍTIMAS DE QUEIMADURAS EXPOSTAS A CURATIVO SEM SEDAÇÃO EM ENFERMARIA
}

\author{
ANALYSIS OF THE BEHAVIOR OF CHILDREN VICTIMS OF \\ BURNINGS DURING SURGICAL DRESSING WITHOUT \\ ANESTHETICAL DRUGS IN INFIRMARY
}

Fabiana Pereira Sabino de Oliveira ${ }^{1}$

Eleonora Arnaud Pereira Ferreira ${ }^{2}$

Vera Ribeiro Novaes ${ }^{3}$

Jeisiane dos Santos Lima ${ }^{3}$

Oliveira FPS et al. Análise do comportamento de crianças vítimas de queimaduras expostas a curativo sem sedação em enfermaria. Rev Bras Crescimento Desenvolv Hum. 2009; 19(3): 369-382.

\section{Resumo:}

O caráter aversivo de muitos procedimentos médicos é amplamente divulgado na literatura. Tais procedimentos são considerados como estressores em potencial, principalmente no caso de pacientes pediátricos vítimas de queimaduras. $\mathrm{O}$ acidente por queimadura é responsável por uma experiência extremamente aversiva para a criança. Associados a ele estão os efeitos negativos ao desenvolvimento adequado dessa criança, decorrentes da hospitalização e de procedimentos médicos invasivos utilizados no tratamento. As crianças vítimas de queimaduras são constantemente submetidas à realização de procedimentos, como curativos, fisioterapia, que são tidos como extremamente aversivos e inerentes ao tratamento. Este estudo teve como objetivo principal analisar os comportamentos emitidos por crianças vítimas de queimaduras durante procedimento de curativo sem sedação realizado em enfermaria. Participaram seis crianças com idades entre seis e doze anos. Utilizou-se: (a) roteiro de entrevista semi-estruturado com perguntas sobre dados sociodemográficos e questões referentes ao acidente que ocasionou a queimadura, e (b) escala de observação de distresse comportamental (Observation Scale of Distress Behavior [OSDB]). Os resultados apontam que todas as crianças apresentaram uma freqüência de comportamentos concorrentes superior a 80\%, em comparação aos comportamentos não-concorrentes. Houve um maior predomínio das categorias comportamentais: protestar (43\%), comportar-se de modo nervoso (24\%) e chorar (20\%). Dentre as categorias de comportamentos não concorrentes, as que tiveram a maior freqüência foram: falar (37,5\%) e responder verbalmente (25\%). Dessa forma, ressalta-se que procedimentos médicos invasivos necessitam de intervenções que visem à diminuição do sofrimento comportamental da criança.

Palavras-chave: crianças vítimas de queimaduras; psicologia pediátrica; escala de observação de distresse comportamental; observação direta do comportamento.

1 Psicóloga, Doutoranda no Programa de Pós-Graduação em Teoria e Pesquisa do Comportamento, Universidade Federal do Pará.

2 Professora no Programa de Pós-Graduação em Teoria e Pesquisa do Comportamento, Universidade Federal do Pará.

3 Graduanda do curso de Psicologia da Universidade Federal do Pará.

Instituição onde o trabalho foi realizado: Hospital Metropolitano de Urgência e Emergência.

Correspondência para: Eleonora Arnaud Pereira Ferreira. End: BR 316, Km 2, Cond. City Park, Rua A, Casa 5, Atalaia, CEP: 67.013-070, Ananindeua-Pará, Fone: (91) 32353902 / (91) 81113915. E-mail: eleonora@ufpa.br

Trabalho realizado durante o curso de doutorado da primeira autora, no Programa de Pós-Graduação em Teoria e Pesquisa do Comportamento. 


\begin{abstract}
:
The aversive nature of many medical procedures is widely available in the literature. These procedures are considered as potential stressors, especially in pediatric patients affected by burns. Burning is a highly aversive experience for the child. Associated with it are the negative effects to the proper development of children resulting from hospitalization and invasive medical procedures used in treatment. Child victims of burns are constantly exposed to procedures such as dressings, physiotherapy, which are regarded as extremely aversive and related to treatment. This study aimed to analyse behaviors of children suffering burns during dressing procedure performed without sedation in the ward. Attended six children aged between six and twelve years. Used: (a) roadmap for semi-structured questions on sociodemographic data and questions relating to the accident which caused the burn, and (b) scale of behavioral observation (Observation Scale of Behavioral Distress [OSDB]). The results indicate that all children had a higher frequency of behaviors competitors to $80 \%$, as opposed to non-competitive behavior. There was a higher prevalence of behavioral categories: protesting (43\%), behave nervously (24\%) and crying (20\%). Among the categories of not competitor behavior, those which had the greatest frequency were: talking (37.5\%) and answering (25\%). Thus, invasive medical procedures require interventions aimed at reducing the suffering of children..
\end{abstract}

Key words: child victims of burns, pediatric psychology; observational scale of distress behavior, direct observation of behavior.

\section{INTRODUÇÃO}

No curso de seu desenvolvimento, a criança pode se defrontar com situações adversas, tanto orgânicas quanto psicossociais. ${ }^{1,2} \mathrm{Em}$ muitos destes casos, a hospitalização pode ser necessária, expondo a criança aos impactos deste novo ambiente (o hospitalar), o qual, apesar de ter a finalidade de promover a melhora da sua saúde, acaba adquirindo um caráter ameaçador e invasivo. ${ }^{3}$

Em trabalhos sobre hospitalização infantil é abordada, frequentemente, a experiência de pacientes no manejo de procedimentos invasivos, considerando-se este como um estressor em potencial durante a hospitalização de crianças..$^{4-7}$

De acordo com a literatura, os estudos que visam identificar e avaliar os comportamentos emitidos durante a execução de procedimentos médicos invasivos utilizam predomi- nantemente a Observation Scale of Distress Behavior (OSDB) como instrumento de medida. Esta escala de observação comportamental foi adaptada no Brasil por Borges ${ }^{8}$ e Costa $\mathrm{Jr}^{5}$ Originalmente, a escala era composta por 11 categorias morfológicas de comportamento, as quais indicam o sofrimento experienciado pela criança durante a execução de procedimentos médicos invasivos.

O estudo de Costa Jr. ${ }^{5}$ possibilitou a criação e/ou o aprimoramento de categorias funcionais de comportamentos de crianças submetidas à punção venosa (PV) para quimioterapia (QT), além de excluir algumas categorias originárias da OSBD pelo fato de não se adequarem ao ambiente utilizado para a realização do trabalho. $\mathrm{O}$ autor estabeleceu dois grupos de comportamentos distintos em sua funcionalidade, que foram denominados de comportamentos concorrentes e comportamentos não concorrentes. 
Os comportamentos concorrentes seriam aqueles que acarretam dificuldades, atrasos ou impedimentos à execução do procedimento médico invasivo, ou que necessitam de uma ação física por parte do agente executor. No estudo de Costa Jr. ${ }^{5}$ esses comportamentos foram: agredir fisicamente, choramingar, chorar, comportar-se de modo nervoso, fugir, gritar, movimentar-se até a imobilização, e protestar. Já os comportamentos não concorrentes seriam aqueles que não dificultam e/ou tendem a facilitar a execução do procedimento médico invasivo, como: auxiliar a execução do procedimento médico invasivo, buscar suporte emocional, falar, responder verbalmente, e solicitar informação.

Além dos fatores aversivos advindos do próprio tratamento, é possível que a sensação de ter parte do corpo invadida por equipamentos e instrumentos faça com que a criança perceba a situação como ameaçadora ${ }^{9}$, o que aumenta a probabilidade de emissão de comportamentos concorrentes, como os comportamentos de fuga/esquiva, dificultando a adesão ao tratamento pela criança.

Considerando-se que o conceito de adesão envolve a participação ativa do paciente nas decisões sobre seu tratamento, destaca-se a necessidade de análises sobre os fatores que estariam promovendo ou dificultando esta adesão, a qual engloba uma série de comportamentos como: tomar medicação, fazer curativos, seguir dietas, entre outros. ${ }^{10}$

A adesão também engloba a compreensão dos benefícios em seguir o tratamento, bem como os seus custos para isso. ${ }^{11}$ No caso de pacientes pediátricos vítimas de queimaduras, onde o tratamento é prolongado, quanto mais aversivas forem as situações de curativos, mais aversivo o tratamento irá se tornar.

A adesão demanda do paciente pediátrico e de sua família a aprendizagem de novos comportamentos, a modificação de sua rotina e a tolerância ao desconforto proveniente de procedimentos médicos.
Desta forma, o repertório comportamental da criança e/ou de seu cuidador deve ser considerado na condução do tratamento. ${ }^{10} \mathrm{Na}$ literatura, de maneira geral, se utilizam intervenções diretas com a criança, a fim de promover a adesão desta ao tratamento. Pois, se a criança apresenta comportamentos colaboradores, o procedimento pode ser mais rápido e a equipe médica realizará o procedimento de modo mais satisfatório ao perceber a participação da criança.

Além disso, os comportamentos colaboradores do paciente pediátrico podem influenciar o tempo de permanência desta no hospital uma vez que, colaborando com os procedimentos, a lesão ou a patologia podem ser mais bem cuidadas, favorecendo uma boa evolução do quadro clínico da criança e até antecipar a alta hospitalar.

Autores interessados em investigar os efeitos negativos da hospitalização destacam a influência de procedimentos invasivos para o prejuízo ao desenvolvimento adequado de crianças. ${ }^{4,6,7,12-15}$

A necessidade de um alto grau de colaboração por parte do paciente pediátrico durante a execução de procedimentos médicos, especialmente os de natureza invasiva, pode tornar a execução do procedimento uma tarefa árdua devido a inúmeros comportamentos de não-colaboração emitidos pela criança. Entretanto, poucos trabalhos em psicologia têm estudado o efeito de intervenções psicossociais, de forma sistemática, sobre o comportamento de crianças expostas a consultas e tratamentos de saúde, principalmente quando as contingências envolvem procedimentos invasivos, como curativos em pacientes vítimas de queimaduras.

Os acidentes por queimaduras, geralmente, apresentam-se como uma experiência extremamente aversiva, fator este agravado quando as vítimas se tratam de crianças que são as principais vítimas. ${ }^{16-19}$ Martins e Andrade ${ }^{18}$ relatam que a epidemiologia apresentada pelo DATASUS para o ano de 2006 
foi de 16.573 internações de crianças e adolescentes menores de 15 anos vítimas de queimaduras, onde as queimaduras representaram 14\% das internações por causas externas no Brasil.

Os traumas por queimaduras são responsáveis por sequelas indeléveis e as reações emocionais apresentadas a este tipo de acidente iniciam-se desde o momento do acidente, permeiam o processo de tratamento e, na maioria das vezes, acompanham a criança depois da mesma receber alta hospitalar e voltar para o seu ambiente familiar. ${ }^{20}$ Guerrero ${ }^{21}$ acrescenta que, além de constituir um atentado à integridade física das vítimas, a queimadura representa uma experiência de grande potencial traumático devido ao alto grau de dor, a destruição de tecidos, órgãos ou membros, assim como alterações da imagem corporal e sensibilidade da pele.

Os procedimentos dolorosos necessários para o tratamento da queimadura incluem os procedimentos de punção venosa para administração de remédios, limpeza das lesões, enxertia, desbridamentos e trocas de curativos, além de fisioterapia. ${ }^{19}$

Quanto à realização de curativos em pacientes vítimas de queimaduras, há a possibilidade de estes serem feitos com ou sem sedação. A sedação refere-se à condição onde o paciente fica sob efeito de medicação anestésica, sem emissão de comportamentos, e é realizada em bloco cirúrgico com a presença de médico anestesista. Quanto ao curativo sem sedação, este acontece na própria enfermaria do paciente, ou em uma sala de curativo específica, onde o mesmo permanece consciente e orientado, interagindo com os profissionais.

A realidade hospitalar revela que muitos profissionais subestimam a dor em função da reação do paciente, realizando procedimentos sem sedação e analgesia adequadas. ${ }^{22-24}$ Isso reafirma a proposta de inserção de instrumentos que auxiliem na mensuração da dor em crianças, haja vista que estes conduzirão ao melhoramento do processo de tratamento ou na escolha da conduta terapêutica. ${ }^{17,24}$

Assim, o objetivo é analisar os comportamentos concorrentes e não concorrentes de crianças vítimas de queimaduras durante a realização de procedimento de curativo sem sedação, atendidas em um hospital de referência para o tratamento de queimaduras e traumas.

\section{MÉTODO}

\section{Participantes}

Trata-se de estudo descritivo, na forma de série de casos, que participaram seis crianças vítimas de queimaduras, com idades entre seis e 12 anos e seus respectivos acompanhantes. Utilizaram-se os seguintes critérios de inclusão: criança internada vítima de queimadura na faixa etária de seis a 12 anos; acompanhante com idade superior a 18 anos, superfície corpórea de queimadura na criança inferior a 70\%, crianças que tivessem previsão médica de realizar curativo em enfermaria sem sedação e que tanto criança quanto acompanhante aceitassem participar do estudo (Projeto aprovado pelo Comitê de Ética sob o Protocolo no. 024/2008, CEP- NMT/UFPA).

\section{Local da Coleta de Dados}

O estudo foi realizado no Setor de Pediatria do Hospital Metropolitano de Urgência e Emergência (HMUE), hospital de referência para o atendimento a pacientes vítimas de traumas e queimaduras, localizado na região metropolitana de Belém-PA. Nesse setor, o HMUE dispõe de 20 leitos para demandas diversas e 10 leitos de pediatria no Centro de Tratamento ao Paciente Queimado (CTQ).

As crianças diariamente são avaliadas pela equipe médica do CTQ. Sendo assim, cabe a estes profissionais estabelecerem a conduta de tratamento a ser adotada a fim de favorecer o quadro clínico da criança. Desta forma, dependendo de variáveis como a gravidade da 
lesão, a extensão e o tempo de internação (com sucessivas realizações de curativos em bloco cirúrgico), cabe à equipe de cirurgia plástica, avaliar e programar os curativos a serem realizados.

Comumente, as crianças passam por um período de internação onde o curativo somente é realizado em bloco cirúrgico. Logo que as lesões passam a evoluir positivamente ao tratamento médico, a cirurgia plástica encaminha os pacientes a fazerem curativos sem sedação em enfermaria. Tal procedimento é realizado por técnicos de enfermagem e enfermeiros, além dos médicos, que são solicitados a avaliar a lesão do paciente.

Não há um número exato de idas ao bloco cirúrgico antes que o procedimento seja realizado em enfermaria sem sedação, estando este condicionado à melhora clínica do paciente. A presença do acompanhante durante a realização deste procedimento nem sempre é permitida, por se tratar de uma situação aversiva a este que, muitas vezes por opção própria prefere não estar presente durante o procedimento. No presente estudo, todas as sessões de curativo que foram analisadas não tiveram a presença do acompanhante da criança.

\section{Materiais e instrumentos utilizados para a coleta de dados}

Foram utilizados: (a) um roteiro de entrevista semi-estruturado que incluía perguntas sobre dados sociodemográficos e questões referentes ao acidente que ocasionou a queimadura, (b) a versão revisada da Escala de Observação do Distresse Comportamental ${ }^{5}$, e (c) uma filmadora da marca Sony, modelo DCR-DVD610.

\section{Procedimento de Coleta de Dados}

Os acompanhantes das crianças internadas na enfermaria do CTQ, que correspondessem aos critérios de inclusão, eram convidados a participar do estudo mediante a leitura e assinatura do Termo de Con- sentimento Livre e Esclarecido (TCLE). Depois da autorização assinada, deu-se início à aplicação dos instrumentos. O cuidador respondeu ao roteiro de entrevista semi-estruturado para levantamento de dados sociodemográficos e das circunstâncias em que ocorreu o acidente. A aplicação foi feita de forma individual, na enfermaria onde a criança estava internada.

Em seguida, foi observada e gravada em vídeo, uma sessão de curativo com cada uma das seis crianças participantes, todas sem analgesia. A gravação do procedimento ocorreu no momento em que iniciou o curativo e foi realizada por pesquisadoras treinadas no uso do equipamento. Considerou-se como término da sessão de observação o momento em que a equipe encerrava o procedimento ausentandose da sala.

\section{Análise dos dados}

Os dados coletados neste estudo foram mensurados qualitativa e quantitativamente. Duas pesquisadoras foram previamente treinadas na utilização da OSDB, por meio da análise do caso de uma criança em situação de curativo semelhante à utilizada no estudo principal. Durante o treinamento, fez-se o cálculo de concordância entre as observadoras, obtendo-se um valor de concordância superior a $80 \%$. As sessões analisadas no presente estudo foram assistidas pelas duas pesquisadoras de forma individual e analisadas de acordo com as ocorrências e não ocorrências das categorias de comportamentos das crianças, considerando-se intervalos de 15 segundos. Foi obtido um índice de concordância superior a $80 \%$ na etapa de registro dos comportamentos dos participantes da pesquisa.

As categorias analisadas a partir da OSDB seguiram o mesmo padrão proposto por Costa Jr. ${ }^{5}$, adaptando-se as funcionalidades de cada categoria de acordo com a população pesquisada. Sendo assim, as categorias obedeceram a classificação apresentada na Tabela 1. 
Tabela 1: Categorias de comportamentos concorrentes e de comportamentos não-concorrentes e seus exemplos

\section{Comportamentos Concorrentes}

Agredir fisicamente (AF)

Choramingar (CM)

Chorar (CH)

Comportar-se de modo nervoso (CN)

Fugir (FG)

Gritar (GR)

Movimentar-se até imobilização (IM)

Protestar (PR)

\section{Exemplo}

Morder, socar ou dar tapas, beliscar e chutar.

anh, anh, anh

Evocar lágrimas e sons não verbais.

Tremer, roer unhas, franzir a testa.

Ausentar-se da sala onde o procedimento é realizado.

]

Evocar sons de intensidade alta, sem emissão de palavras.

Resistir ao procedimento até que seja contido fisicamente.

Reclamar com veemência, rebelar-se. Exemplo: "Pára, não quero isso, 'tá doendo, deixa que eu tiro".

\section{Comportamentos Não Concorrentes}

Auxiliar na execução do procedimento (AE)

Buscar suporte emocional (SE)

Falar (FA)

Responder Verbalmente (RV)

Solicitar informação (SI)

\section{Exemplo}

- Deixa que eu vou tirar a atadura.- Vou molhar para sair mais rápido.

- Chama a minha mãe; eu quero a minha mãe.

- Acho que é ambulância chegando; tenho um sinal aqui.

Auxiliar de enfermagem:- Essa é a área doadora? Criança: - É.

- Pode molhar essa atadura? - Que óleo é esse?

\section{RESULTADOS}

\section{Caracterização das crianças e de seus acom- panhantes}

Conforme observado na Tabela 2, a faixa etária das crianças variou de seis a 12 anos de idade, com igual distribuição entre os gêne- ros. A respeito da situação escolar, havia dois participantes (P3 e P4) que estavam cursando série não correspondente a sua idade e um (P6) que não estava matriculado em nenhuma instituição de ensino. A maioria era procedente do interior do estado ( $n=4$ de 6 ) e morava com os pais e irmãos ( $\mathrm{n}=5$ de 6 ). 
Tabela 2: Dados sociodemográficos das crianças e de seus acompanhantes.

\begin{tabular}{|c|c|c|c|c|c|c|c|}
\hline & & Participantes & & & & & \\
\hline & & $\mathrm{P} 1$ & $\mathrm{P} 2$ & P3 & P4 & P5 & P6 \\
\hline \multirow{6}{*}{ 莺 } & Idade (anos) & 6 & 9 & 11 & 10 & 7 & 12 \\
\hline & Gênero & Feminino & Masculino & Feminino & Feminino & Masculino & Masculino \\
\hline & Série & Alfabetização & $4^{\mathrm{a}}$ série & $4^{\mathrm{a}}$ série & $1^{\mathrm{a}}$ série & $2^{\mathrm{a}}$ série & Não estudava \\
\hline & Procedência & Interior & Interior & Grande Belém & Interior & Grande Belém & Interior \\
\hline & Organização & Pais e 3 & Mãe, padrasto & Pais e 2 & Pais e 2 irmãos & Pais e 2 irmãos, & Pais e 3 irmãos \\
\hline & Familiar & irmãos maiores & e irmão menor & rmãos maiores & menores e 1 maior & 1 menor, 1 maior & menores \\
\hline \multirow{5}{*}{ 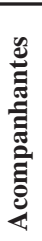 } & Parentesco & Mãe & Padrasto & Mãe & Pai & Tia & Cons. tutelar \\
\hline & Tutelar & Tutelar & Tutelar & Tutelar & Tutelar & Tutelar & Tutelar \\
\hline & Tutelar & Tutelar & Tutelar & Tutelar & Tutelar & Tutelar & Tutelar \\
\hline & Situação & Casada & Casado & Casada & Casado & Solteira & Casado \\
\hline & Conjugal & Auxiliar de Cozinha & Pescador & Dona de Casa & Lavrador & Estudante’ & $\begin{array}{l}\text { Técnico em Saúde } \\
\text { e Cons. Tutelar }\end{array}$ \\
\hline
\end{tabular}

Ainda na Tabela 2, observa-se que a maioria dos acompanhantes era membro da família nuclear, com exceção de P5, cujo cuidador era a tia (irmã adotiva do pai) e de P6, na qual a responsabilidade fora atribuída a um conselheiro tutelar, devido ao pai encontrar-se gravemente doente, a mãe apresentar "problemas psiquiátricos" e ausência de parentes consanguíneos para cuidar da criança du- rante o período de internação. A idade dos acompanhantes estava na faixa de 19 a 46 anos e, somente o cuidador de $\mathrm{P} 4$ não tinha escolaridade.

\section{Características do contexto do acidente}

Todos os participantes relataram lembrar como acontecera o acidente e foram capazes de contá-lo, conforme descrito na Tabela 3.

Tabela 3: Contexto em que ocorreu o acidente que ocasionou a queimadura

\begin{tabular}{|c|c|c|c|c|c|}
\hline Crianças & Gênero & $\begin{array}{l}\text { Idade } \\
\text { (anos) }\end{array}$ & $\begin{array}{l}\text { Local do } \\
\text { Acidente }\end{array}$ & Contexto & $\begin{array}{c}\text { Presença de } \\
\text { acompanhante na } \\
\text { ocasião do acidente } \\
\end{array}$ \\
\hline P1 & Feminino & 6 & Domicílio & $\begin{array}{l}\text { Brincando com a irmã pela casa onde residia, } \\
\text { bateu no cabo da frigideira que fritava batata } \\
\text { e o óleo quente derramou sobre a criança. }\end{array}$ & Sim \\
\hline P2 & Masculino & 9 & Domicílio & $\begin{array}{l}\text { Sozinho em casa, ao tentar acender a } \\
\text { lamparina derramou acidentalmente álcool } \\
\text { líquido no corpo e quando fora acendê-la, o } \\
\text { fogo espalhou sobre si. }\end{array}$ & Não \\
\hline P3 & Feminino & 11 & Domicílio & $\begin{array}{l}\text { Na cozinha, enquanto a mãe fazia café, após } \\
\text { a mesma colocá-lo sobre a mesa, um menino } \\
\text { que estava na rua chutou uma bola que bateu } \\
\text { na garrafa de café e derramou o líquido } \\
\text { quente sobre o colo da criança. }\end{array}$ & Não \\
\hline P4 & Feminino & 10 & Domicílio & $\begin{array}{l}\text { Fazendo café para os irmãos menores, às } \\
\text { cinco horas da manhã, o fogo pegou seu } \\
\text { vestido e se alastrou. Na tentativa de apagá- } \\
\text { lo, queimou os braços. }\end{array}$ & Sim \\
\hline P5 & Masculino & 7 & Domicílio & $\begin{array}{l}\text { Brincando de super-herói, o álcool pegou } \\
\text { fogo e queimou as pernas e abdômen. }\end{array}$ & Sim \\
\hline P6 & Masculino & 12 & Domicílio & $\begin{array}{l}\text { A casa pegou fogo enquanto a criança } \\
\text { dormia. A mãe retirou apenas os irmãos mais } \\
\text { novos e “esqueceu” o participante, que } \\
\text { sofreu queimaduras na face, pescoço e } \\
\text { braços devido ao calor do fogo. }\end{array}$ & Sim \\
\hline
\end{tabular}


É possível observar na Tabela 3 que, ainda que a maioria dos participantes estivesse na presença de um adulto, isto não foi suficiente para evitar o acidente. É visto também que todos os acidentes ocorreram no domicílio da criança.

\section{Características das queimaduras}

Na Tabela 4 é possível observar que, para quase todos os participantes (exceto P1), a área atingida pela queimadura envolveu os membros, sejam eles superiores e/ou inferiores, além de apresentaram queimaduras de segundo grau. Três participantes (P2,

P4 e P5) apresentaram Superfície Corporal Queimada (SCQ) em torno de 30\%.

Observa-se que foram crianças que além de ficarem com áreas extensas do corpo atingidas, tiveram lesões dolorosas e tempo de in-

Tabela 4: Características das queimaduras das crianças

\begin{tabular}{ccccc}
\hline Crianças & $\begin{array}{c}\text { Agente causador } \\
\text { da queimadura }\end{array}$ & $\begin{array}{c}\text { Área atingida } \\
\text { pela queimadura }\end{array}$ & $\begin{array}{c}\text { Grau da } \\
\text { queimadura }\end{array}$ & $\begin{array}{c}\text { Sempo de } \\
\text { SCQ }\end{array}$ \\
\hline internação
\end{tabular}

* SCQ: Superfície Corporal Queimada.

ternação superior a 20 dias. Vale ressaltar que $\mathrm{P} 4$ foi o participante que permaneceu mais tempo internado e P6, ainda que tivesse apresentado uma SCQ pequena, apresentou também um tempo de permanência prolongado.

\section{Análise dos comportamentos observados durante o procedimento de curativo}

A partir da análise da OSDB, os dados registrados foram distribuídos considerando- se o tempo total de duração do procedimento para cada participante, a quantidade de intervalos de 15 segundos observados, além de registro da frequência relativa de comportamentos concorrentes e de comportamentos não concorrentes, os quais podem ser observados na Tabela 5.

Pôde-se observar que a duração média do procedimento de curativo foi de 22 minutos, aproximadamente, sendo o menor tempo

Tabela 5: Tempo de duração do curativo, total de intervalos de 15' e porcentagem de emissões de comportamentos concorrentes e não-concorrentes por participante

\begin{tabular}{|c|c|c|c|c|c|}
\hline Crianças & Tempo & $\begin{array}{l}\text { Duração do Curativo } \\
\text { Total de } \\
\text { Intervalos de } 15\end{array}$ & $\begin{array}{c}\text { OSBD } \\
\text { Intervalos com } \\
\text { emissão de } \\
\text { comportamentos alvos* }\end{array}$ & $\begin{array}{c}\text { Comportamentos } \\
\text { Concorrente }\end{array}$ & $\begin{array}{c}\text { Comportamentos } \\
\text { Não } \\
\text { Concorrente }\end{array}$ \\
\hline$P 1$ & 12’ $12 "$ & 48 & 34 & $85,3 \%$ & $14,7 \%$ \\
\hline$P 2$ & $33^{\prime} 17 "$ & 134 & 117 & $82,9 \%$ & $17,1 \%$ \\
\hline P3 & 21'32" & 86 & 80 & $96,2 \%$ & $3,8 \%$ \\
\hline P4 & 38 ' & 156 & 137 & $82,5 \%$ & $17,5 \%$ \\
\hline P5 & $21^{\prime} 30$ ’’ & 86 & 49 & $93,9 \%$ & $6,1 \%$ \\
\hline$P 6$ & $34^{\prime} 35^{\prime \prime}$ & 139 & 109 & $84,4 \%$ & $15,6 \%$ \\
\hline
\end{tabular}

* Foram considerados comportamentos alvos aqueles que estivessem de acordo com as categorias descritas na OSDB.

(12 minutos) dispensado para P1, e o maior (38 minutos) para P4. Todos os participantes apresentaram mais de $80 \%$ de emissões de com- portamentos concorrentes ao procedimento de curativo. É importante ressaltar que o participante P3 teve o seu curativo realizado durante 
o tempo médio de duração, entretanto, foi o participante que apresentou a maior frequência de comportamentos concorrentes.

Os intervalos que foram considerados como sem a emissão de comportamentos alvos, referem-se àqueles intervalos onde a criança ficou sem a manipulação direta de alguém, que ficou aguardando a equipe organizar o material necessário para realizar o procedimen- to ou que ficou aguardando a presença de algum outro membro da equipe (enfermeiro ou médico) para que este viesse avaliar o seu curativo. Tais comportamentos não são considerados na OSDB.

Na Tabela 6 estão apresentadas as frequências totais por categorias de comportamentos (concorrentes e não-concorrentes) observadas durante as sessões de curativo.

Tabela 6: Freqüência das categorias de comportamentos emitidos pelas crianças durante a realização do procedimento de curativo sem sedação em enfermaria

\begin{tabular}{llrr}
\hline Comportamentos & Categorias & $f a$ & $\%$ \\
\hline Concorrentes & Agredir fisicamente (AF) & 0 & 0 \\
& Choramingar (CM) & 27 & $6,00 \%$ \\
& Chorar (CH) & 93 & $20,12 \%$ \\
& Comportar-se de modo nervoso (CN) & 108 & $24,00 \%$ \\
& Fugir (FG) & 0 & 0 \\
& Gritar (GR) & 9 & $6,00 \%$ \\
& Movimentar-se até imobilização (IM) & 4 & $0,88 \%$ \\
& Protestar (PR) & 193 & $43,00 \%$ \\
& L Não-concorrentes & 434 & $86 \%$ \\
\hline & Auxiliar na execução do procedimento (AE) & 11 & $15,27 \%$ \\
& Buscar suporte emocional (SE) & 4 & $5,56 \%$ \\
& Falar (FA) & 27 & $37,50 \%$ \\
& Responder Verbalmente (RV) & 18 & $25,00 \%$ \\
& Solicitar informação (SI) & 12 & $16,67 \%$ \\
& L & 72 & $14 \%$ \\
\hline & Total & 506 & $100 \%$ \\
\hline
\end{tabular}

De um total de 506 episódios observados, $86 \%$ correspondeu a comportamentos classificados como concorrentes. Destes, os mais frequentes foram protestar (43\%), comportarse de modo nervoso (24\%) e chorar (20\%). Dentre os não concorrentes, os mais frequentes foram falar $(37,50 \%)$, responder verbalmente (25\%) e solicitar informação (16,67\%). Destaca-se que, neste estudo, não foram observados comportamentos correspondentes a agredir fisicamente e a fugir.

A Figura 1 apresenta a ocorrência de comportamentos concorrentes apresentados individualmente pelas crianças.
Conforme apresentado na Figura 1, a categoria Protestar (PR) foi prevalente para os participantes P2, P3 e P6. Somente P4 emitiu comportamentos que precisaram de imobilização (IM). A categoria Gritar (GR) foi predominante apenas para a participante P1. Choramingar (CM) teve frequência baixa para todos os participantes.

Quanto aos comportamentos não concorrentes registrados durante o procedimento de curativo sem sedação, estes foram analisados funcionalmente, com o intuito de identificar variáveis que pudessem auxiliar na execução dos mesmos. A Figura 2 apresenta a frequên- 


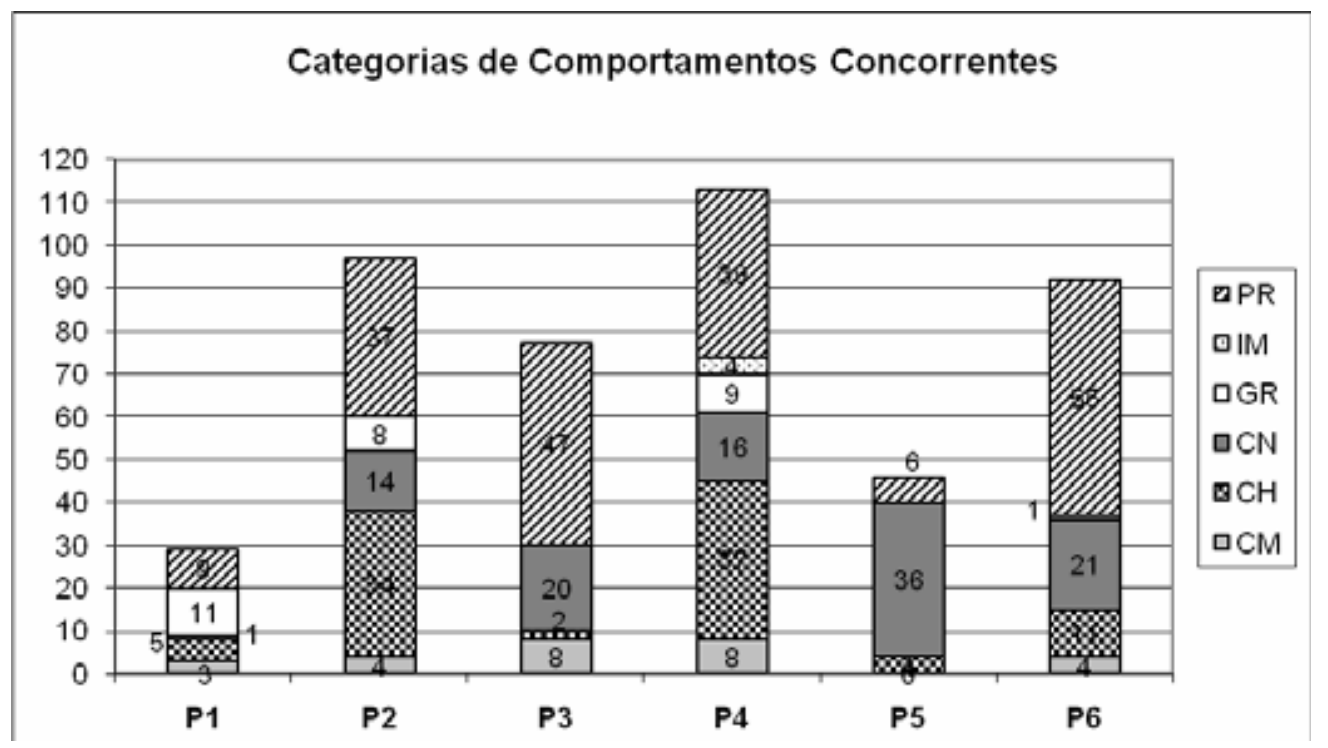

Figura 1: Freqüência absoluta das categorias de comportamentos concorrentes emitidos pelas crianças durante o curativo sem sedação

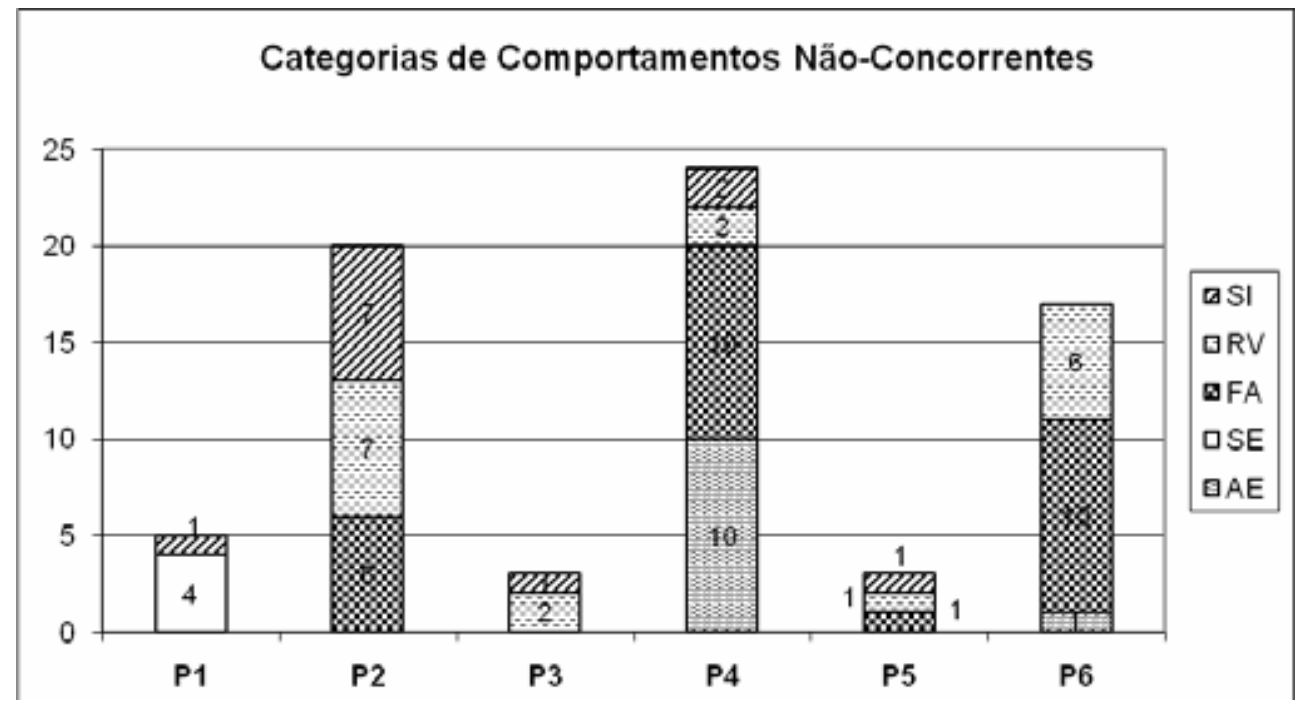

Figura 2: Freqüência absoluta das categorias de comportamentos não concorrentes emitidos pelas crianças durante o curativo sem sedação.

cia total dos comportamentos não-concorrentes por criança.

Fica evidenciado, a partir da observação da Figura 2, que a participante P4 apresentou maior ocorrência de comportamentos não concorrentes, seguida de P2. Os participantes P3 e P5 foram os que apresentaram a menor frequência de comportamentos não concorrentes.
Com o intuito de identificar variáveis que pudessem contribuir com o aumento de emissões de comportamentos não concorrentes ao procedimento, os comportamentos emitidos pela equipe de enfermagem durante a realização do procedimento foram analisados e agrupados em categorias. Desta forma, foram identificadas quatro categorias 
comportamentais referentes a comportamentos emitidos pelo profissional de enfermagem: (a) ignorar, correspondendo a comportamentos que demonstrem indiferença em relação à emissão de comportamentos da criança; (b) criticar, correspondendo a comportamentos do profissional de enfermagem que julgue de modo irônico ou pejorativo o comportamento emitido pela criança durante o procedimento; (c) responder a questionamento, referindo-se ao comportamento verbal emitido pelo profissional de enfermagem diante de uma pergunta feita pela criança; e (d) dar atenção, incluindo comportamentos da equipe de enfermagem que correspondam às solicitações ou questionamentos feitos pela criança, demonstrando consideração pela mesma, de modo a favorecer a emissão de novos comportamentos por parte da criança.

Os dois primeiros, ignorar e criticar, podem ser classificados como inadequados para o contexto, uma vez que indicam insensi- bilidade do profissional às demandas da criança. Os outros dois, responder questionamento e dar atenção, podem ser classificados como mais adequados para o contexto pois sugerem sensibilidade do profissional para atender às demandas da criança durante a realização do procedimento.

Foram observados 72 episódios correspondentes a comportamentos emitidos pela equipe de enfermagem, direcionados às crianças durante a realização do procedimento de curativo sem sedação em enfermaria. Desses, a maioria foi classificada na categoria ignorar $(\mathrm{n}=29)$, seguido de dar atenção $(\mathrm{n}=19)$, criticar $(\mathrm{n}=14)$ e responder questionamento $(\mathrm{n}=10)$.

Na Tabela 7, a frequência total de emissão de cada comportamento não concorrente emitido pelas crianças é visualizada em comparação com a correspondente frequência dos comportamentos emitidos pela equipe de enfermagem.

Tabela 7: Freqüência de comportamentos não concorrentes emitidos pelas crianças relacionada à freqüência das categorias comportamentais emitidas pela equipe de enfermagem

\begin{tabular}{|c|c|c|c|}
\hline $\begin{array}{c}\text { 'Comportamentos não } \\
\text { concorrentes emitidos } \\
\text { pelas crianças }\end{array}$ & Freqüência total & $\begin{array}{l}\text { Comportamentos emitidos } \\
\text { pela equipe de } \\
\text { enfermagem }\end{array}$ & $\begin{array}{l}\text { Freqüência } \\
\text { total }\end{array}$ \\
\hline Solicitar Informação & 12 & $\begin{array}{c}\text { Responder Questionamento } \\
\text { Ignorar }\end{array}$ & $\begin{array}{l}8 \\
4\end{array}$ \\
\hline Responder Verbalmente & 18 & $\begin{array}{l}\text { Dar Atenção } \\
\text { Criticar } \\
\text { Ignorar }\end{array}$ & $\begin{array}{c}11 \\
4 \\
3\end{array}$ \\
\hline Falar & 27 & $\begin{array}{c}\text { Ignorar } \\
\text { Dar Atenção } \\
\text { Criticar }\end{array}$ & $\begin{array}{c}14 \\
7 \\
4\end{array}$ \\
\hline $\begin{array}{l}\text { Buscar Suporte Emocional } \\
\text { Auxiliar na Execução }\end{array}$ & $\begin{array}{c}4 \\
11\end{array}$ & $\begin{array}{c}\text { Responder Questionamento } \\
\text { Ignorar } \\
\text { Criticar } \\
\text { Ignorar } \\
\text { Dar Atenção }\end{array}$ & $\begin{array}{l}2 \\
4 \\
6 \\
4 \\
1\end{array}$ \\
\hline
\end{tabular}

Fica evidenciado na Tabela 7 que, de um total de 12 episódios nos quais as crianças solicitaram informações (SI), em oito elas foram atendidas em seus questionamentos e em quatro estas foram ignoradas pela equipe de enfermagem. Em 18 episódios onde as crianças responderam verbalmente (RV) às demandas dos profissionais, em onze estes lhes deram atenção, em quatro foram criticadas e em três foram ignoradas. Dentre os 27 episódios de fala (FA) das crianças, em 14 estas foram ignoradas pelos profissionais, em sete receberam atenção, em quatro foram criticadas e em apenas dois episódios obtiveram respostas 
a seus questionamentos. Em todos os quatro episódios em que as crianças buscaram suporte emocional (SE), foram ignoradas pela equipe de enfermagem. Nos 11 episódios nos quais as crianças procuraram auxiliar na execução do procedimento (AE), em seis foram criticadas, em quatro foram ignoradas e em apenas um episódio receberam atenção dos profissionais.

\section{DISCUSSÃO}

O tratamento necessário para a criança vítima de queimadura inclui procedimentos dolorosos, como o curativo, que podem, em longo prazo, interferir no desenvolvimento da criança, confirmando os dados apresentados por Pedromônico ${ }^{2}$ ao afirmar que o desenvolvimento infantil pode ser prejudicado caso a criança seja exposta a situações adversas. No presente estudo, a maioria dos comportamentos observados nas crianças correspondeu à categoria de comportamentos concorrentes (acima de $80 \%$ ), com destaque para protestar (43\%), comportamento nervoso (24\%) e chorar (20\%), sugerindo que estas crianças foram expostas a um contexto de intenso sofrimento.

Crepaldi e Hackbarth ${ }^{3}$ ressaltam a influência negativa que a hospitalização pode acarretar na vida da criança. No caso de crianças vítimas de queimaduras, isso ganha maior relevância pois, como foi mostrado no presente estudo, a exposição a procedimentos invasivos e dolorosos, associada ao tempo de internação prolongado, pode favorecer o surgimento de sequelas negativas para a criança. ${ }^{21}$

Guerrero $^{21}$ e Torritesi e Vendrúsculo ${ }^{24}$ destacam a relevância de se identificar a dor percebida pelo paciente quando submetido a situações dolorosas, pois tal percepção pode ser acentuada aumentando o desconforto e ansiedade do paciente. Tal afirmação foi eviden- ciada neste estudo no caso de P1, P3 e de P6, pois, quando questionados pela equipe de enfermagem se estavam chorando porque o procedimento estava doendo, os mesmos responderam: não, é mais medo (sic).

A utilização de escalas que identifiquem o sofrimento comportamental, como a OSDB, reafirma a necessidade de instrumentos de medida que possam embasar intervenções pontuais a partir dos resultados obtidos, confirmando as afirmações de Damasceno ${ }^{17}$ e Torritesi e Vendrúsculo. ${ }^{24}$

Quanto às categorias de comportamentos concorrentes, a categoria Protestar teve maior frequência em P2, P3, P4 e P6. Ainda que tal categoria tenha sido predominante, foi observado que a criança não se opõe à realização do mesmo. No caso de P4, que precisou ser imobilizada, isto aconteceu independentemente de a paciente solicitar auxiliar no procedimento, o que nem sempre fora atendido pela equipe de enfermagem.

Todas as crianças apresentaram comportamentos nervosos antes do início do procedimento. Isto pode ter ocorrido em decorrência de um processo de condicionamento, no qual a criança passou a antecipar as condições aversivas às quais seria exposta.

Foi identificada a necessidade de rever as categorias propostas pela escala OSDB, para adequar o instrumento a esta população. Originalmente, esta escala fora desenvolvida e adaptada para procedimentos específicos com um tempo de duração reduzido, como a punção venosa em contexto de quimioterapia. ${ }^{5}$ Algumas categorias propostas na escala, como agredir fisicamente e fugir, não foram observadas durante o procedimento de curativo sem sedação em crianças vítimas de queimaduras. Observou-se que, embora estas crianças verbalizassem sua vontade de não realizar o procedimento, estavam impossibilitadas de fugir da situação, por estarem com áreas do corpo imobilizadas o que dificultava sua locomoção. Desta forma, alguns comportamentos 
que foram observados nestas crianças, os quais poderiam ser classificados como colaboradores ao procedimento, como permitir ser manipulada, permanecer quieta, atender à solicitação do profissional, não são quantificados pela OSDB.

Ainda que as crianças tenham emitido uma frequência baixa de comportamentos não concorrentes em comparação à frequência de comportamentos concorrentes, foi observado que aqueles nem sempre eram reforçados pela equipe de enfermagem, contrariando recomendações de especialistas. ${ }^{3-7,12,15}$ Em algumas situações, a equipe consequenciava os comportamentos não concorrentes da mesma forma que os concorrentes, demonstrando insensibilidade às necessidades da criança, favorecendo a aversividade do ambiente hospitalar. $3,4,8,13$

Embora a equipe de enfermagem não tenha sido objeto principal de investigação neste estudo, percebeu-se que esta precisa ser treinada e capacitada para que possa identificar os comportamentos não concorrentes das

\section{REFERÊNCIAS}

1. Zannon, C.M.L.C. Psicologia aplicada à Pediatria: Questões metodológicas atuais. In: R.R. Kerbauy (Org.), Comportamento e saúde: Explorando alternativas. Santo André, SP: Arbytes Editora; 1999: 46-58.

2. Pedromônico, M.R M. A relevância da avaliação psicológica na clinica pediátrica. In: M.A.Crepaldi, M.B.M. Linhares \& G.B. Perosa (OrgS.), Temas em Psicologia Pediátrica. São Paulo: Casa do Psicólogo, 2006: 83-107.

3. Crepaldi, M.A. \& Hackbarth, I.D. Aspectos psicológicos de crianças hospitalizadas em situação pré-cirúrgica. Temas em Psicologia da SBP, 2002; 10(2): 99-112.

4. Costa Jr., A.L. Psico-oncologia e manejo de procedimentos invasivos em oncologia pediátrica: uma revisão de literatura. Psicologia: Reflexão e Crítica, 1999; 12(1), 107-118. crianças e consequenciá-los positivamente, de forma que possa contribuir para a realização do procedimento.

\section{CONSIDERAÇÕES FINAIS}

Nos últimos anos houve considerável avanço no tratamento médico de queimaduras. Entretanto, há necessidade de se considerar as variáveis estressoras relacionadas ao tratamento como possíveis desencadeadoras de problemas para o desenvolvimento da criança. Para tal, o uso de escalas que possibilitem a intervenção direcionada a esta população pode ser de grande valia para a redução dos efeitos aversivos advindos com o tratamento. A OSDB mostrou-se eficaz no intuito de identificar o sofrimento comportamental da criança. Entretanto, uma adequação em suas categorias poderia apresentar um grande avanço para auxiliar no planejamento de ações preventivas voltadas para pacientes pediátricos expostos a tratamentos dolorosos.

5. Costa Jr., A.L. Análise de comportamentos de crianças expostas à punção venosa para quimioterapia. Tese de Doutorado não-publicada, Programa de Pós-Graduação em Psicologia, Instituto de Psicologia, Universidade de Brasília. Brasília, DF, 2001.

6. Motta, A.B. \& Enumo, S.R.F. Brincar no hospital: câncer infantil e avaliação do enfrentamento da hospitalização. Psicologia: Saúde e Doenças, 2002; 3(1), 23-41.

7. Motta, A.B. \& Enumo, S.R.F. Brincar no Hospital: estratégias de enfrentamento da hospitalização infantil. Psicologia em Estudo, Maringá, 2004; 9(1), 19-28.

8. Borges, L.M. Treinamento de respostas de enfrentamento e colaboração em mães de crianças submetidas a procedimentos médicos invasivos. Dissertação de Mestrado. Brasília, DF: Universidade de Brasília, 1999. 
9. Possobon, R.F.; Carrascoza, K.C.; Moraes, A.B.A. \& Costa Jr, A.L. O tratamento odontológico como gerador de ansiedade. Psicologia em Estudo, Maringá, 2007; 12(3): 609-616.

10. Ferreira, E.A.P. Adesão ao tratamento em psicologia pediátrica. In M.A.Crepaldi, M.B.M. Linhares \& G.B.Perosa (Orgs.). Temas em Psicologia Pediátrica. São Paulo: Casa do Psicólogo, 2006.

11. Ferreira, E.A.P. Adesão ao tratamento em portadores de diabetes mellitus: efeitos de um treino em análise de contingências sobre comportamentos de autocuidado. Tese de doutorado nãopublicada, Instituto de Psicologia, Universidade de Brasília, 2001.

12. Mitre, R. M.A. \& Gomes, R. A promoção do brincar no contexto da hospitalização infantil como ação de saúde. Ciência \& Saúde Coletiva, 2004; 9 (1), 147-154.

13. Oliveira, G.F., Dantas, F.D. \& Fonsêca, P.N. O impacto da hospitalização em crianças de 1 a 5 anos de idade. Revista da Sociedade Brasileira de Psicologia Hospitalar, 2004; 7(2), 37-54

14. Santos, A.R.R. Psiconcologia pediátrica em hospital escola. In R.R. Kerbauy, (Org.), Sobre comportamento e cognição: Psicologia Comportamental e Cognitiva - Conceitos, pesquisa e aplicação, a ênfase no ensinar, na inovação e no questionamento clínico. Santo André, SP: Arbytes Editora, 2000; (5); 139- 147.

15. Soares, M.R.Z. Estratégias lúdicas na intervenção com crianças hospitalizadas. In: C.G. de Almeida (Org.), Intervenções em grupo: estratégias psicológicas para a melhoria da qualidade de vida. Campinas, SP: Papirus, 2003; 23-36.

16. Castro, D.M., Abrantes, M.M., Lamounier, J.A. \& Lemos, A.T.O. Estudo descritivo de queimaduras em crianças e adolescentes. Jornal de Pediatria, 1999; 75 (3), 181-186.
17. Damasceno, A.K.C. Epidemiologia de dor em crianças vítimas de queimaduras. Tese de doutorado. Universidade Federal do Ceará, Fortaleza; 2005.

18. Martins, C.B.G. \& Andrade, S.M.

Queimaduras em crianças e adolescentes: análise da morbidade hospitalar e mortalidade. Acta Paulista de Enfermagem, 2007; 20 (4), 464-469.

19. Rossi, L.A., Camargo, C., Santos, C.M.N.M., Barruffin, R.C.P. \& Carvalho, E.C. A dor da queimadura: terrível para quem sente, estressante para quem cuida. Revista latino-americana de enfermagem, 2000; 8(3), 18-26.

20. Silveira, E.T. \& Moulin, A.F.V.

Primeiros Socorros - queimaduras, insolação e internação. Disponível no site: http://

www.saudeemmovimento.com.br/ conteudos/ conteudo_exibe1.asp?cod_noticia=1135. Obtido em 14 de fevereiro de 2009.

21. Guerrero, G.Z. Reacciones emocionales de los niños hospitalizados com quemaduras así como de sus familiares. Revista Latino-americana de Psicopatologia Fundamental, 2008; 11(1), 29-38.

22. Menossi, M.J., Lima, R.A.G. \& Corrêa, A.K. (2008). Pain in children and adolescents with cancer. Revista Latinoamericana de Enfermagem, 16 (3), 489-494.

23. Correia, L.L. \& Linhares, M.B.M. Avaliação do comportamento de crianças em situações de dor: revisão da literatura. Jornal de Pediatria, 2008; 84(6), 477-486.

24. Torritesi, P. \& Vendrúsculo, D.M.S. A dor na criança com câncer: modelos de avaliação. Revista Latino-americana de Enfermagem, 1998; 6(4): 49-55.

Recebido em 28 de maio de 2009. Modificado em 03 de agosto de 2009. Aceito em 25 de agosto de 2009. 